\title{
Observations on the Mechanism of Erythrocyte Sickling
}

\author{
JAMES G.White ${ }^{[23]}$ \\ Department of Pediatrics, University of Minnesota Medical School, Minneapolis, Minnesota, USA
}

\begin{abstract}
Extract
Recent studies have shown that the fundamental mechanism underlying the distortion of sickled erythrocytes is the conversion of reduced sickle cell hemoglobin ( $\mathrm{HbS}$ ) into rods. The abnormal molecules appear to stack into $65 \AA$ filaments that, through parallel association, form twisted rods $180-190 \AA$ in diameter. In the present investigation, the effect of hemolysis on parallel bundles of rods in sickled cells has been examined. Hemolysis was found to destroy the framework of rods in the reverse stages of formation. The rods broke down into filaments, which disappeared into amorphous debris. To further characterize the nature of the sickling phenomenon, the structure of hemoglobin crystals formed in canine erythrocytes by freeze-thaw was examined. The structure differed significantly from rods of sickled hemoglobin. Results of these investigations support the concept that sickling is a process of sol-gel transformation, not of intracellular crystallization.
\end{abstract}

\section{Speculation}

Precise arrangement of $\mathrm{HbS}$ molecules in the rods formed when intact erythrocytes sickle under reduced oxygen tension has not been defined. The phenomenon of stacking of $\mathrm{HbS}$ molecules into $65 \AA$ filaments before aggregation of the 170-190 $\AA$ rods is supported by this study. It is not certain, however, whether the rod is an aggregate of twisted filaments like the microtubule, or an ascending filamentous spiral of molecular subunits resembling tobacco mosaic virus. Clarification of the molecular arrangement is important for understanding the mechanism of sickling and essential for the selection of chemical agents potentially capable of disassembling or preventing formation of rods of HbS.

\section{Introduction}

Two major theories have been advanced to explain the sickling phenomenon. One suggests that distortion of susceptible erythrocytes results from conversion of soluble sickle hemoglobin ( $\mathrm{HbS}$ ) to a gel-like substance when exposed to reduced oxygen tension, while the other purports that sickling is due to nonspecific crystal- lization of $\mathrm{HbS}$ in the deoxygenated state. PAuling [13] favored the first concept when he suggested that defective molecules of reduced sickle hemoglobin might form into rods causing distortion of susceptible erythrocytes, in essence, a sol-gel transformation. HARRIS [5] later gave substance to this theory by demonstrating bundles of parallel rods, or tactoids, in concentrated solutions of $\mathrm{HbS}$ exposed to low oxygen tension. 
In contrast, PERUTz [15] noted the relative insolubility of reduced $\mathrm{HbS}$ compared with deoxygenated normal hemoglobin. This and other observations [14] led him to conclude that sickling was due to the intracellular crystallization of the abnormal molecules. Formation of crystalline lattices would force free water into unoccupied compartments of the erythrocyte, resulting in alterations in osmotic pressure. Diffusion of free water out of the cell would permit the surface membrane to collapse on the crystals, resulting in the severe distortions observed in sickled erythrocytes.

In 1958, Bessis et al. [3] studied thin sections of osmic acid-fixed sickled erythrocytes in the electron microscope. A felt-like pattern of irregular fibers was noted in the cytoplasm of the altered cells. As a result, Bessis suggested that sickling was a sol-gel transformation and not crystallization of HbS. Stetson [16] came to a different conclusion after examining the fine structure of sickled erythrocytes fixed initialy in chilled glutaraldehyde before a second fixation in osmium. He observed a series of parallel lines in sickle cell cytoplasm, which on cross section appeared to demarcate hexagonal spaces. The empty honeycomb arrangement resembled a crystalline lattice consistent with the theory that sickling was due to the intracellular crystallization of $\mathrm{HbS}$.

Murayama's [12] investigations included an examination of whole mount preparations of concentrated hemoglobin from hemolyzed sickle cells. He observed bundles of hollow rods under the electron microscope and suggested that sickling was due to aggregation of $\mathrm{HbS}$ into microtubules similar to those found in most other types of cells. A recent report from this laboratory [18] supports Murayama's findings. Sickled erythrocytes prepared in glutaraldehyde at $37^{\circ}$ before osmic acid fixation contained bundles of parallel rods generally oriented in the long axis of distortion. The rods of $\mathrm{HbS}$ were rarely hollow in cross section and, therefore, were not morphologically identical to microtubules. The gross resemblance of fibers of $\mathrm{HbS}$ to microtubules, however, and the disappearance of the fibers in chilled sickled erythrocytes suggested that rods of $\mathrm{HbS}$ were protein polymers markedly similar to microtubules found in other cells.

In the present study, the effect of trauma on sickled erythrocytes and the structure of hemoglobin crystals formed in canine erythrocytes after freezing have been examined. The results further clarify the mechanism of sickling, suggest a basis for the delayed hemolysis of injured sickled erythrocytes, and separate the sickling process from crystallization of hemoglobin.

\section{Materials and Methods}

The techniques used routinely in this laboratory for collection of blood in citrate anticoagulant, induction of the sickling phenomenon in vitro, fixation of blood samples in glutaraldehyde at $37^{\circ}$ and then in chilled osmic acid, dehydration in alcohol, and embedding in Epon 812 have been described [17, 18, 19]. Identical methods were employed for the present study.

\section{Preparation of Traumatized Sickled Cells}

The increased mechanical fragility of sickled erythrocytes is well known [7]. In order to examine the process of hemolysis in sickled erythrocytes, the cells were exposed to trauma in a tissue homogenizer, a glass tube with a fitted nylon pestle driven by a small electric motor. This type of equipment is ordinarily employed for preparation of subcellular fractions. Samples of normal and sickle blood combined with $1 \%$ sodium metabisulfite were added to the system in order to determine the speed and duration of exposure that would produce minimal hemolysis of normal cells, but appreciable damage to sickled erythrocytes. The damage was determined grossly by observing the color change produced by hemoglobin appearing in supernatant plasma after homogenization. Samples of normal and sickled cells were then homogenized in the apparatus and prepared for study in the electron microscope by fixation in glutaraldehyde and osmic acid [18].

\section{Preparation of Hemoglobin Crystals in situ}

The methods available for preparation of crystals of human hemoglobin generally involve chemical manipulation $[2,3]$, or preparation of concentrated hemolysates [4]. The purpose of this study was to compare the structure of hemoglobin crystals found in situ in the least artificial manner possible; therefore, canine erythrocytes were used, since freezing alone will crystallize the hemoglobin in these cells [21]. Resultant crystals examined in the light and phase microscope appeared identical to crystals obtained from human hemoglobin by other workers [4]. Small angle x-ray diffraction would reveal differences in the structure of molecules, but it is doubtful that crystalline lattices of dog hemoglobin have an organization that differs significantly from crystals of human hemoglobin.

Canine erythrocytes were quick frozen in dry ice and acetone, then placed in liquid nitrogen for thirty minutes. The blood samples were rewarmed by placement in a $37^{\circ}$ water bath. Frozen-thawed erythrocytes were fixed in glutaraldehyde, then in osmic acid, and imbedded in Epon 812. Thin sections of plastic-imbedded blood samples and hemoglobin crystals were stained with uranyl acetate and lead citrate. All obser- 
vations were made in a Phillips 200 electron microscope.

\section{Results}

\section{Appearance of Sickled Cells}

The fine structure of sickled hemoglobin in silu has been described [18]. Moderately distorted erythrocytes were filled with an irregular meshwork of fibers varying from $65 \AA$ filaments to $190 \AA$ rods. Crescentric sickled cells contained bundles of parallel 180-190 \& rods generally oriented in the long axis of distortion. Each rod was separated from adjacent rods by an interval of less dense cytoplasm. On cross section, the rods rarely appeared hollow, but appeared to be composed of a variable number of subfilaments in parallel association (figs. 1A, 1 B, 1 C, 2A, and 2 B).

The structure of reduced hemoglobin $\mathrm{S}$ in situ suggested that individual $\mathrm{HbS}$ molecules stacked into long filaments that formed relations with adjacent filaments, resulting in the $190 \AA$ rods. In order to further establish this mechanism of sickling, the reverse process was followed during hemolysis of sickled cells.

\section{Appearance of Traumatized Sickled Cells}

Normal erythrocytes exposed to homogenization for brief periods revealed some damage. Ghosts and diluted red cells occurred more frequently than in control samples. The extent of damage, however, was much greater in samples of sickled erythrocytes homogenized for the same period and at the same speed. Most sickled cells were injured, although some intact cells with characteristic internal structure were observed. The majority of injured cells revealed changes intermediate between undamaged cells and swollen empty ghosts. A clear area was evident at the periphery of the cells, but a large mat of irregular fibers occupied the central cytoplasm. Residual bundles of parallel rods were noted. For the most part, however, the irregular meshwork consisted of filaments of variable size ranging from $65 \AA$ and rods up to the $190 \AA$. Many damaged cells had large, clear halos containing unorganized debris and small mats of irregular threads. The swollen ghost cells containing amorphous debris and no filaments or fibers appeared to represent end products of the hemolytic process (figs. $3 \mathrm{~A}, 3 \mathrm{~B}$, and $3 \mathrm{C}$ ).

\section{Structure of Hemoglobin Ciry'stals}

Frozen and thawed canine erythrocytes revealed severe damage. The cells were swollen and clear halos were observed under the distended surfaces similar to those seen in partially hemolyzed sickled erythrocytes. Large, extremely regular inclusions were apparent in the cytoplasm of the damaged cells. The structures revealed a three-dimensional periodicity characteristic of crystals viewed in thin section under the electron microscope. The major period of parallel lines was $70 \AA$ center to center; the angular patterns had similar intervals. Crystals observed in the canine erythrocytes bore no resemblance to the substructure noted in sickled cells (figs. $4 \mathrm{~A}$ and $4 \mathrm{~B}$ ).

\section{Discussion}

The hemoglobin-rich cytoplasm of normal erythrocytes is devoid of substructural organization when thin sections are viewed under the electron microscope. Fully oxygenated sickle cells have the same biconcave discoid shape as normal erythrocytes and contain no evidence of cytoplasmic fibers. Only susceptible erythrocytes manifesting distortions characteristic of the sickling phenomenon after exposure to low oxygen tension or reducing agents reveal fibrous transformation of internal substance [18]. Cells that are mildly altered contain a complex web of fibers varying from $65 \AA$ filaments to $190 \AA$ rods. Massively sickled erythrocytes are filled with bundles of parallel rods generally oriented in the long axis of distortion. The severity of alteration appears closely related to the extent that cytoplasmic substance is converted to rods and to the degree of organization of rods into parallel bundles.

The conversion of sickle cell hemoglobin ( $\mathrm{HbS})$ in the reduced state into parallel bundles of rods appears to be the basic mechanism underlying the sickling phenomenon. Pauling [13] first suggested that the abnormal hemoglobin might form rods, and both Harris [5] and Murayama [12] demonstrated the presence of bundles of rods in concentrated hemoglobin solutions obtained from hemolyzed sickle cells. The occurrence of parallel bundles of rods in intact sickled erythrocytes confirms the findings of these workers and

Fig. 1. Erythrocytes from a paticnt with sickle cell anemia. The cells were sickled with $1 \%$ sodium metabisulfite, fixed in glutaraldehyde at $37^{\circ}$, then in chilled osmic acid, and imbedded in Epon 812. Thin sections through the cytoplasm of the sickled red cells reveal a plethora of internal organization never seen in normal erythrocytes. In $1 \mathrm{~A}$ the cells marked 1 and 2 contain an irregular meshwork of fibers. The fibers in cell 3 are organized in parallel bundles running in the horizontal and vertical axes of distortion. $1 B$ and $1 C$ demonstrate the high degree of organization of the rods of $\mathrm{HbS}$ in parallel bundles. Most of the bundles of rods parallel the long axis of the cell, but some are seen, lying in different planes (fig. 1B). Mag. $1 \mathrm{~A} \times 19,700 ; 1 \mathrm{~B} \times$ 36,$800 ; 1 \mathrm{C} \times 22,400$. 
$1 \mathrm{~A}$
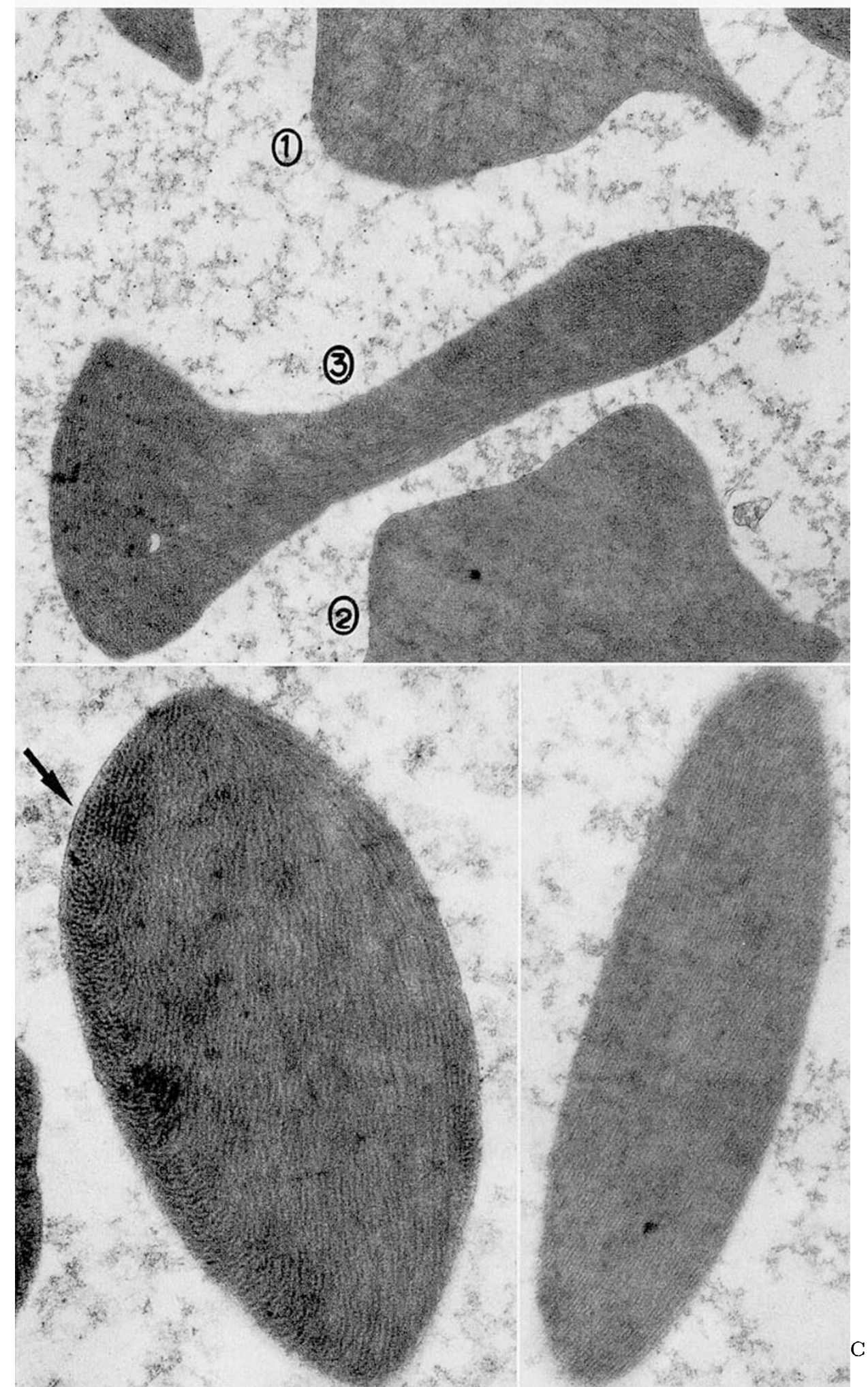

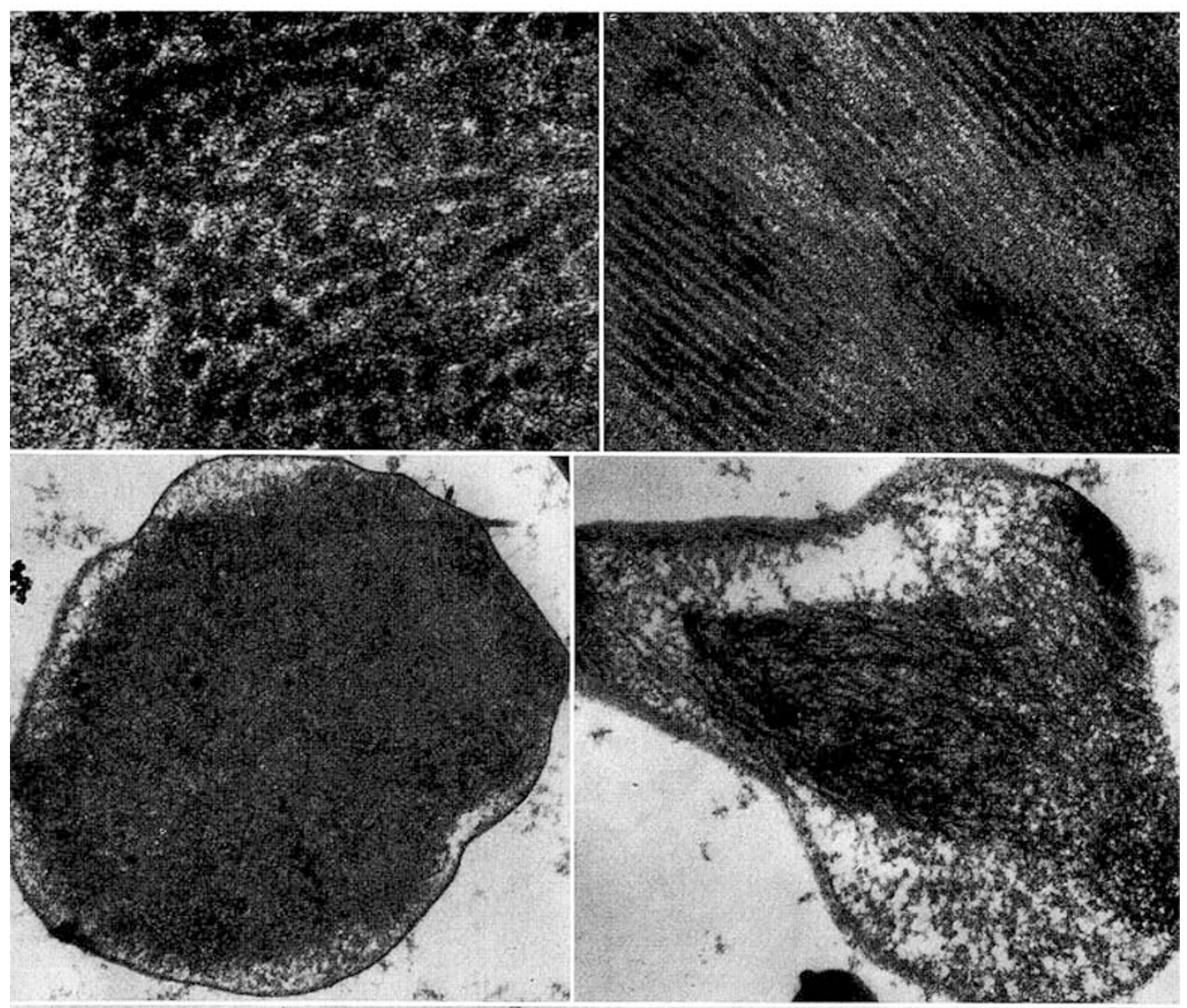

$3 \mathrm{~A}$

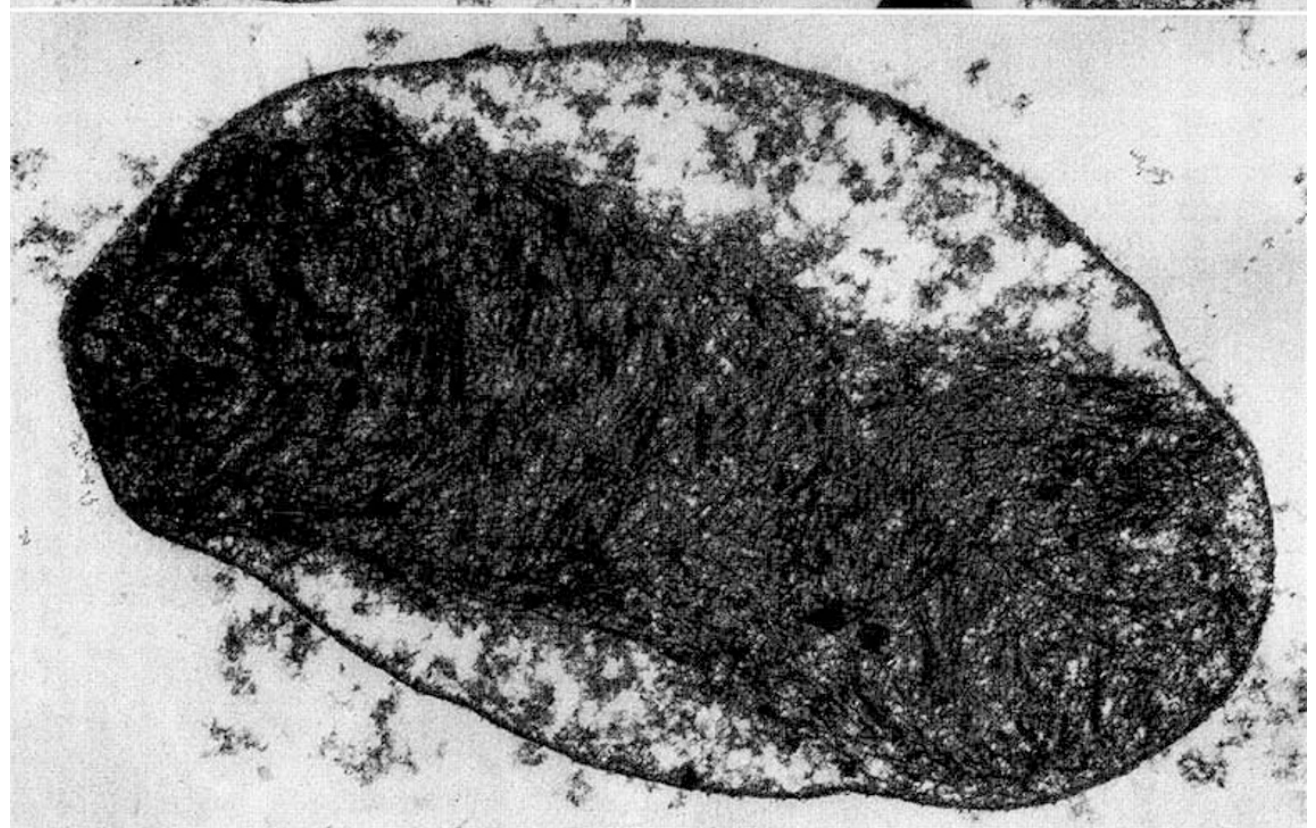


supports their concept of the sickling mechanism. Molecules of reduced $\mathrm{HbS}$ appear to stack end-to-end to form $65 \AA$ long filaments, and adjacent parallel filaments interact to form $180-190 \AA$ rods capable of distorting erythrocyte shape $[12,18]$.

Study of hemolysis in sickled erythrocytes exposed to trauma adds additional support for this concept. Injury to sickled erythrocytes permitted plasma water to pass into the damaged cells. The framework of parallel rods was torn apart as swelling increased, but the destruction appeared to be time consuming. $\mathrm{HbS}$ in the reduced state is relatively insoluble [14], and the organized bundles of rods appeared to resist the attack by increased intracellular water. Thus, damaged sickled cells were not immediately converted to ghosts, but revealed all stages of transformation. The resistance of the subcellular structures to breakdown after cell injury that was observed in this study most likely explains why sickled cells damaged by laser beams take time to develop into ghosts [9].

The breakup of bundles of parallel rods during hemolysis of sickled cells appears to reverse the process of formation. Rods do not simply disappear, but are first cleaved into smaller filaments, which are then destroyed. This additional evidence supports the concept that molecular stacking into filaments precedes the formation of rods of $\mathrm{HbS}[12,18]$.

Chemical and physical features of the sickling phenomenon [6] and the absence of crystalline structures in the cells [3] suggest that the process is basically a

Fig. 2. The appearance of sickled hemoglobin in situ. The transected rods in $2 A$ reveal the presence of filamentous compounds in their substructure. Parallel rods in $2 C$ resemble microtubules when sectioned in this plane, but are rarely hollow, as shown in $2 \mathrm{~A}$ on cross section. The $180-190 \AA$ rods are regularly separated from each other by an interval of 30-90 $\AA$. Mag. $2 \mathrm{~A} \times 171,000 ; 2 \mathrm{~B} \times 99,000$.

Fig.3. Sickled erythrocytes after exposure to homogenization. The damaged cells occasionally appear as swollen empty ghosts. For the most part, however, they retain masses of hemoglobin despite the injury. Residual hemoglobin is present in the form of irregular mats rather than in highly organized bundles of parallel 180-190 $\AA$ rods. Fibers making up the meshwork of hemoglobin strands vary from $65 \AA$ filaments to rods three times the diameter of filaments. The filaments and rods are torn apart at the periphery of the hemoglobin mass and appear as amorphous debris under the swollen cell surface. $3 A, 3 B$, and $3 C$ reveal various aspects of the destruction of the framework of sickled hemoglobin in different cells. Mag. $3 \mathrm{~A} \times 20,400 ; 3 \mathrm{~B}$ $\times 27,600 ; 3 \mathrm{C} \times 42,300$. sol-gel transformation. The similarity of rods of $\mathrm{HbS}$ to microtubules supports this concept [12]. Labile microtubules are found in abundance in most types of celis [10], and the tubular structures are assembled and disassembled under conditions [17] and by chemical agents [1] known to affect sol-gel transformation. Rods of $\mathrm{HbS}$ are not identical to microtubules, because they are composed of a different protein molecule and are rarely hollow in thin section. Rods of $\mathrm{HbS}$ are sensitive to pressure and chilling [12], however. They can be dissolved and their formation prevented by high concentrations of colchicine [20], even though this agent has a low affinity for hemoglobin [1]. Thus, rods of $\mathrm{HbS}$ are protein polymers markedly similar to microtubules and, on this basis alone, the sickling phenomenon would appear to be a sol-gel transformation.

The structure of hemoglobin crystals in intact cells was examined before the theory that sickling is due to intracellular crystallization of reduced $\mathrm{HbS}$ was discarded. Crystals formed in canine erythrocytes by freeze-thaw revealed the high degree of order characteristic of crystalline structures observed under the electron microscope [8]. The hemoglobin molecules were stacked in long filaments $65 \AA$ in diameter, similar to the filaments observed in sickled cells, and were in parallel association, as were the filaments in rods of $\mathrm{HbS}$; however, the resemblance ends there. The parallel filaments of hemoglobin crystals are oriented in flat sheets layered one on top of another, like laminated plywood. Each sheet of parallel filaments is ordered to the layer above and below, resulting in the threedimensional lattice of a crystal. In contrast, parallel filaments forming rods of $\mathrm{HbS}$ are twisted together, forming a structure resembling a rope or wire cable [12].

The difference between the crystals and rods may be related to the mechanism of molecular stacking. Individual molecules of reduced $\mathrm{HbS}$ join in a key-inlock fashion [12]. The asymmetry of individual molecules causes a slightly offset association at each junction and results in a natural helix. Parallel association of helices may cause torsion on the aggregate, preventing development of flat sheets and promoting formation of rods with a repeating axial twist. The molecular association in crystals of hemoglobin appears highly symmetrical, and this symmetry may account for the association of parallel filaments in sheet-like layers rather than in twisted rods.

The fundamental difference between hemoglobin crystallization and the sol-gel transformation underlying the sickling phenomenon may be slight. For the crystal chemist, the difference may be only a matter of degree [11]; any molecular ordering beyond the amorphous state may be interpreted as crystallization. The importance of separating the sickling of $\mathrm{HbS}$ from 


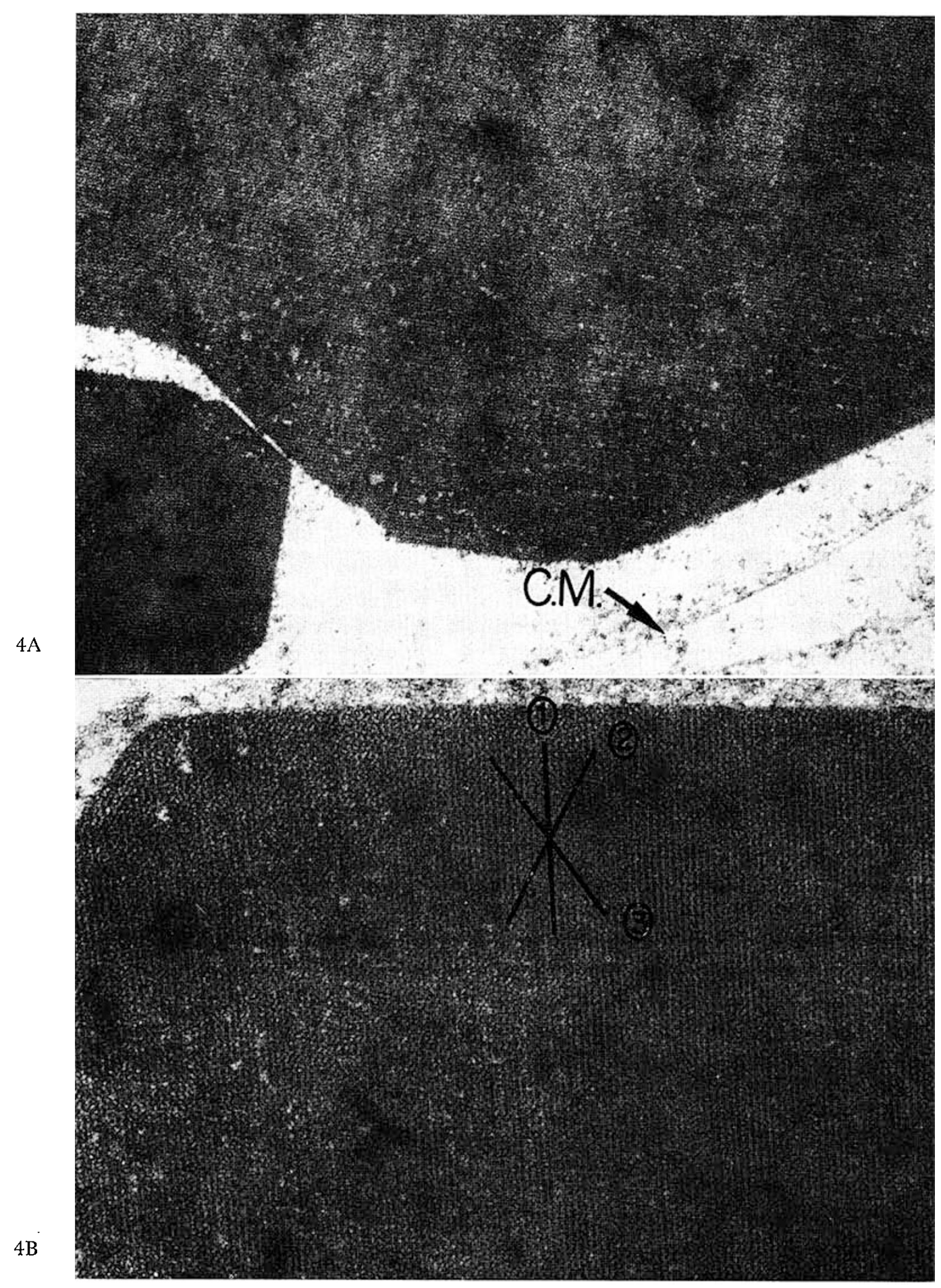


the phenomenon of crystallization, however, is not merely semantic. The chemical and physical factors that influence sol-gel transformation differ from those affecting crystallization [6]. By demonstrating that sickling is indeed a sol-gel transformation, it is possible to concentrate on the drugs and physical conditions that affect this process [20]. Control of gelling in susceptible erythrocytes would prevent sickling and would eliminate the morbid clinical features of sickle cell disease. Investigations designed to accomplish this goal are currently in progress.

\section{References and Notes}

1. BORISY, G.G. and TAYLOR, E.W.: The mechanism of action of colchicine: Binding of colchicine ${ }^{3} \mathrm{H}$ to cellular protein. J. Cell Biol. 34: 525 (1967).

2. Bessis, M.: The blood cells and their formation; in: The cell (ed. Brachet, J. and Mirskley, A. E.) (Academic Press, New York 1961).

3. Bessis, M. ; Nomarski, G.; Thiery, J.P. et BretonGorius, J.: Etudes sur la falciformation des globules rouges en microscope polarisant et en microscope électronique. II. L'intérieur du globule. Comparison avec les cristeaux intraglobulaires. Rev.Hématol. 13: 429 (1958).

4. Drabkin, D.L.: A simplified technique for a large scale crystalization of human oxyhemoglobin. Isomorphous transformations of hemoglobin and myoglobin in the crystalline state. Arch. Biochem. 21: 224 (1949).

5. Harris, J.W.: Studies on the destruction of red blood cells. VII. Molecular orientation in sickle cell hemoglobin solutions. Proc. Soc. exp. Biol., N.Y. 75: 197 (1950).

6. HARRIS, J.W.: The role of physical and chemical

Fig.4. Crystals formed in canine erythrocytes after freeze-thaw. Hemoglobin masses are retained within the damaged erythrocytes under the swollen cell membranes as shown in $4 A$ (C.M.). The hemoglobin masses. have a highly ordered structure compared to the mats of fibers left in the cytoplasm of damaged sickled cells. The degree of order is evident in the crystal shown in $4 B$. A periodic pattern of parallel filaments is evident in three planes. Each filament is separated from adjacent filaments, and the center-to-center interval is $70 \AA$. The triaxial pattern evident in the hemoglobin masses is characteristic of a crystalline lattice. This type of order does not occur in sickled erythrocytes. Mag. $4 \mathrm{~A} \times$ 75,$900 ; 4 \mathrm{~B} \times 154,000$. factors in the sickling phenomenon. Progr. Hematol. vol. 2 (Grune and Stratton, New York 1959).

7. HARris, J.W.: The red cell (Harvard University Press, Cambridge, Mass. 1963).

8. HoldSWORTH, R.H.: The presence of a crystalline matrix in pyrenoids of the diatom, Achnanthes Brevipes. J. Cell Biol. 37: 831 (1968).

9. Jensen, W.N.; Bromberg, P.A. and Bessis, M.: Microincision of sickled erythrocytes by a laser beam. Science 155: 704 (1967).

10. Ledbetter, M. C. and Porter, K. M.: A 'microtubule' in plant cell fine structure. J. Cell Biol. 19: 239 (1963).

11. MABIS, A.J.: Structure of mesomorphic phases. Acta Crysta. 15: 1152 (1962).

12. Murayama, M.: Molecular mechanism of red cell sickling. Science 153: 145 (1966).

13. Pauling, L.: Harvey Lect. 12: 216 (1955).

14. Perutz, M.F.; Liquori, A.M. and Errich, F.: X-ray and solubility studies of haemoglobin of sickle-cell anemia patients. Nature, Lond. 167: 929 (1951).

15. Perutz, M.F. and Mrtchison, J.M.: The sickling phenomenon with special reference to the differentiation of sickle cell anemia from sickle cell trait. Nature, Lond. 166: 677 (1950).

16. Stetson, C.A.: The state of sickled hemoglobin in sickled erythrocytes. J. exp. Med. 123: 341 (1966).

17. White, J.G.: An ultrastructural basis for the alterations induced in platelets by chilling. Blood 30: 625 (1967).

18. White, J.G.: The fine structure of sickled hemoglobin in situ. Blood 31: 561 (1968).

19. White, J.G.: Fine structural changes induced in platelets by adenosine disphosphate. Blood 31: 604 (1968).

20. White, J.G. and Krivit, W.: Induction of the sickling phenomenon in erythrocytes exposed to glutaraldehyde. J. Cell Biol. 32: 141A (1967).

21. Francis Westling, Ph.D., Assistant Professor, Department of Mechanical Engineering, University of New Mexico, Albuquerque, New Mexico, brought this fact to my attention, and I am deeply indebted to him for the initial preparations.

22. Supported by grants from the USPHS No.AM 02917, A105153, and CA08832, Cardiovascular Clinical Research Program Project, Minnesota Heart Association, and the Minnesota Division of the American Cancer Society.

23. Requests for reprints should be addressed to: JAMEs G. White, M.D., Department of Pediatrics, University of Minnesota Medical Center, Minneapolis, Minn. 55455 (USA). 